\title{
Special Protection Scheme at BTPS Power Station
}

\author{
Makarand Sudhakar Ballal · Hiralal Murlidhar Suryawanshi · \\ Deepali Makarand Ballal · Mahesh Kumar Mishra
}

Received: 4 December 2012/ Accepted: 12 November 2014/Published online: 13 December 2014

(C) The Institution of Engineers (India) 2014

\begin{abstract}
After 2003 free licensees' act in power sector, it is observed that many power plants from public sector as well as from private sectors are going to be commissioned. The load growth in India is about more than $10 \%$ pa. As these plants are going to connect to the power grid, therefore the grid is going to become more complicated. Also the problems related to grid stability are enhanced. There shall be possibilities regarding failure of grid system and under such circumstance it is always desirable to island minimum single generating unit in power plant of specified geographical area. After islanding the generating unit, this unit has to survive not only for the restoration of grid but also for power supply to important consumers. For the grid stability and effective survival of islanded generating unit, it is mandatory to maintain the power balance equation. This paper focuses on the lacunae's observed in implementation of special protection scheme to carry out islanding operation at Bhusawal Thermal Power Station (BTPS) by considering the case studies. The concepts of islanding, load shedding, generator tripping and along with importance of power balance equation is discussed. Efforts are made to provide the solution for the survival of islanding scheme.
\end{abstract}

M. S. Ballal $(\bowtie) \cdot$ H. M. Suryawanshi

Department of Electrical Engineering, Visvesvaraya National Institute of Technology, Gopal Nagar, South Ambazari Road, Nagpur 440010, Maharashtra, India

e-mail: msb_ngp@rediffmail.com

D. M. Ballal

Maharashtra State Electricity Company Limited,

220 kV Substation, Nagpur, India

M. K. Mishra

Department of Electrical Engineering, Indian Institute of

Technology Madras, Chennai 600 036, India
Keywords Islanded Generating Unit (IGU) - BTPS . Power balance $\cdot$ ECR $\cdot$ GCR $\cdot$ Grid/Radial feeders

\section{Introduction}

The way the power system is operated in this era and therefore the power grid stability is a challenging topic of study for researchers. The problems related to grid failure and its stability are discussed in various literature $[1,2]$. In India after 2003 electricity act, the monopoly of State Electricity Boards (SEBs) regarding power generation, transmission and distribution was ended. Therefore, any private companies or licensees can do this work and thus, day by day it is observed that there is a tremendous enhancement in power sector. However it comes to notice that, all the power plants either existing or private captive power plants or small diesel generating units are going to connect with power grid. These power plants are interconnected for economic benefits, increased reliability and operational advantages as reported in [3]. Deregulation and restructuring have presented new challenges in power systems. Deregulation has defined new objective for power system utilities. The utilities want to maximize their profit and are thus inclined to operate the power system very close to its limits. Moreover, many other factors such as weak connections; unexpected events; hidden failures in protection system; human errors, etc., exist, which in the case of a fault, in a part of the interconnected power system, may lead it towards instability or complete blackout [4]. Power systems in developing countries are even more unreliable and suffer from a large gap between demand and generation; inadequate transmission capacity and large distances between load centers and generation units. Thus, if any contingencies occur in these systems, they would 
have serious consequences such as complete blackout. Therefore, power systems must be more intelligent and flexible to survive such serious events. One of the first measures to avoid such critical events in interconnected power systems is rapid detection of contingencies followed by corrective action such as load shedding to limit the extent of the consequences and prevent islanding or a widespread blackout $[5,6]$. A power system might become unstable if there is any inefficiency in its protection, monitoring and control. Islands, formed by power system controlled islanding schemes can be more stable than naturally formed islands following the occurrence of contingencies.

Controlled islanding can improve restoration of the power system since it creates equilibrium between load and generation. It also helps coherent groups of generators be placed in the same island [7, 8]. Distributed generation (DG) involves the interconnection of small-scale, on-site distributed energy resources (DER) with the main power utility at distribution voltage level [3]. Various impacts of DG connection on existing utility network protection are listed below: $[9,10]$

(i) False tripping of feeders

(ii) Nuisance tripping of protective devices

(iii) Blinding of protection

(iv) Increase or decrease of fault levels with connection and disconnection of DERs

(v) Unwanted islanding

(vi) Prevention of automatic reclosing

(vii) Unsynchronized reclosing

There can be several criteria for initiation of islanding. These are over current, under voltage, over voltage, under frequency, over frequency, etc. Procurement and commissioning of islanding scheme at major power plants and substations is the need of power system for the restoration of grid after failure. In this project of Bhusawal Thermal Power Station (BTPS) under frequency or rather sinking frequency situation is used as the initiating criteria for islanding. The initiation of islanding is required to send trip commands to all grid lines connected to the station. Therefore, islanding scheme should not be complicated and it should be as simple as possible. For successful islanding operation, the disconnection of all grid feeders has to be ensured before tripping any radial feeders. In following sections, the importance of islanding protection, inadvertent islanding, necessary condition for proper islanding and detection of islanding condition are discussed. The islanding scheme applied at BTPS along with four different case studies was presented. At the end, concrete solution is provided for the effective survival of IGU in the constraints of the present islanding scheme.

\section{Concept and Importance of Islanding Scheme}

As per IEEE 2000, an island is 'That part of a power system consisting of one or more power sources and load that is, for some period of time, separated from the rest of the system'. Island operation occurs if one or more generation unit continues to energize a part of the grid after the connection to the rest of the system has been lost. Islanding situations can damage the grid itself or equipments connected to the grid and can even compromise the security of the maintenance personnel that in the grid service. Therefore, according to IEEE1547 standard, islanding state should be identified and disconnected in $2 \mathrm{~s}$. The load shedding, generator tripping and combination of both are discussed below.

\section{Load Shedding}

There are often two load shedding schemes based on under frequency or voltage. One is installed at substation for stability of the grid, wherein frequency setting starts at about $49 \mathrm{~Hz}$. The other is installed at generator plant for stability of the island, where frequency setting is lower than splitting relay. The load-shedding scheme and tie line tripping have been designed by considering the following criteria.

(i) The first stage of load shedding should be activated immediately after the transmission line or feeder has been tripped.

(ii) All generation units should be prevented from tripping caused by the shutdown of auxiliary devices due to voltage sag.

(iii) System frequency has to be maintained above $47 \mathrm{~Hz}$ after line tripping and to be restored to $50 \mathrm{~Hz}$ with the system voltage being recovered more than 0.8 p.u. after the execution of the proposed loadshedding scheme.

\section{Generation Tripping}

The integrity of the separated system cannot be assured solely by load shedding. On the other hand, generation is tripped in islands where the available down regulation exceeds the power generation surplus. These corrective actions modify the system-wide load and the generation vectors such that, the respective system-wide vectors of loads shed and generators are tripped. This sequence continues until the available regulation balances the island load and generation (possibly through a complete loss of load in some islands). Governor systems of generating units are applied for the adjustment of power generation to prevent 
overshooting of system frequency to values higher than 53 $\mathrm{Hz}$.

\section{Load Shedding and Generation Tripping}

Load shedding and generator tripping are carried out by the respective actions of under and over-frequency relays sequentially disconnecting discrete blocks of load or generation. Each frequency-based relay can be adjusted with a frequency deviation action level and a time delay, effectively setting a priority list for load shedding and generation tripping once the island frequency starts to deviate excessively. Such relay coordination may avoid excessive generation tripping or load shedding by permitting primary frequency regulation to bring the island's frequency within the allowable range.

The important necessary condition for controlled islanding is like grid stability condition [2], that is, to maintain power generation and load demand equation always in balance condition. This power balance equation is as below.

$P_{\text {Gen }}=P_{\text {Loss }}+P_{L D}$

where $P_{G e n}$ is the generation output of the unit to which the islanding protection is appiled; $P_{\text {Loss }}$ power loss of the system and $P_{L D}$ load demand pertaining to the concern unit. In this power balance equation, all the three parameters are variable, that is, generation output can be varied by means of governing mechanism [1]. It also depends on various parameters like quality of coal, auxiliaries in service, etc. The system losess depends upon the faults, kind of maintenance, etc. and load demand always depends upon the distribution company's load requirement. Fig. 1 illustrates the diagram for power balance equation as shown in (1). After operation of islanding relaying operation, the essential task is to maintain the concern generating unit, that is, the generating unit should be maintained in islanded condition and it should support the remaining power system for restoration.

The another constraint for the successful survival of IGU is as below.

$P_{\text {Gen min }} \leq P_{\text {Gen }} \leq P_{\text {Gen max }}$

where $P_{G e n \min }$ and $P_{G e n \max }$ are the generation minimum and maximum output of the unit respectively which was

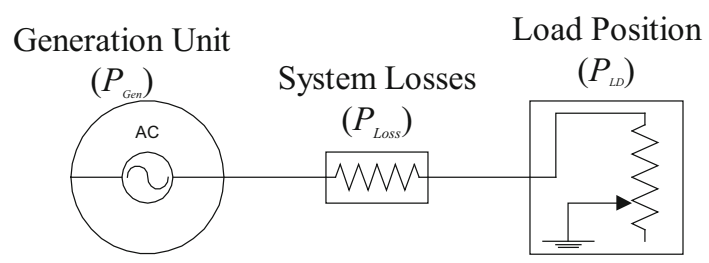

Fig. 1 Schematic of power balance for islanding scheme under islanding condition. The load demand should also be restrained and it should meet the generation output. Therefore, another constraint for the survival of IGU,

$P_{L D \min } \leq P_{L D} \leq P_{L D \max }$

where $P_{L D \text { min }}$ and $P_{L D \text { max }}$ are the minimum and maximum load demand respectively to be fed from the unit which was under islanding condition. From the above constraints, it is clear that the islanding scheme can be survive if,

$P_{G e n} \cong P_{L D}$

In this, it is assumed that the losses are negligible, that is, $P_{\text {Loss }}=0$. From the above constraints, following shall be the essential condition for the effective survival of IGU.

$P_{\text {Gen min }} \leq P_{L D} \leq P_{\text {Gen max }}$

$P_{L D \text { min }} \leq P_{G e n} \leq P_{L D \text { max }}$

From this, one can understand that either the load should be managed in such a way that it should be under the constraint of generation output of IGU or vice versa. Islanding detection often requires coordination to avoid unnecessary operations during faults that do not require tripping of the unit. Finding suitable settings leads to compromise between the sensitivity for islanding detection and selectivity for other disturbances. Probably, the most used new method is called rate of change of frequency (ROCOF), which is based on continuously calculating the gradient of frequency. The gradient is calculated over few cycles and compared with its defined threshold. ROCOF is able to respond to smaller frequency deviations according to their steepness. Islanding is easily detected by the frequency response as illustrated in Fig. 2a. Typical operation settings for ROCOF are between $0.1 \ldots 1.0 \mathrm{~Hz} / \mathrm{s}$ with an operation time of $0.2 \mathrm{~s}, \ldots 0.5 \mathrm{~s}$. Frequency decays slowly and islanding is detected after few seconds is shown in Fig. 2b. At BTPS, sinking frequency situation is used as the initiating criteria for islanding [2].

The most challenging aspect of designing the electrical power system with cogeneration was anti-islanding protection [10]. Major concern of utility grid operation in parallel with DGs is that the DGs do not operate under the direct control of utility grid. The most important operational requirement of the utility is avoiding accidental islanding of any DG site from the utility power source. According to utility, a power island thus formed may complicate the orderly reconnection of the power supply network and may present a potential hazard to the public and utility personnel. Besides, DG power supply can deviate from the required quality standards. Several guidelines have been introduced [11] in G59 to ensure that the presence of the small DGs will not detract from the quality of supply to all customers connected to the system. 


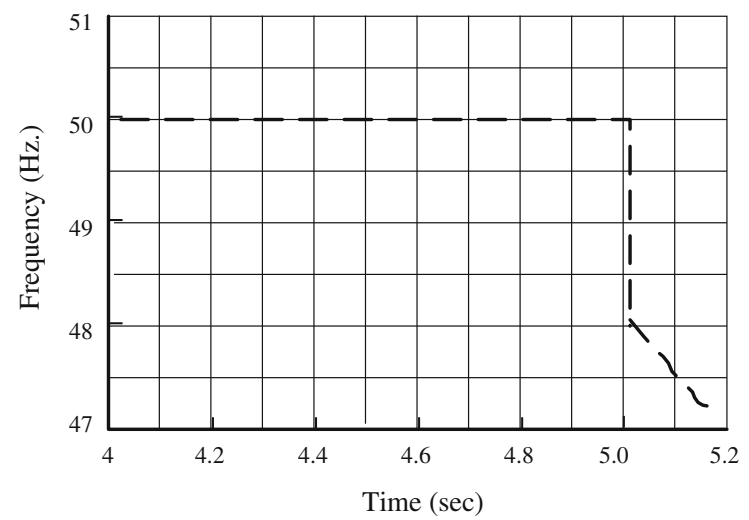

a

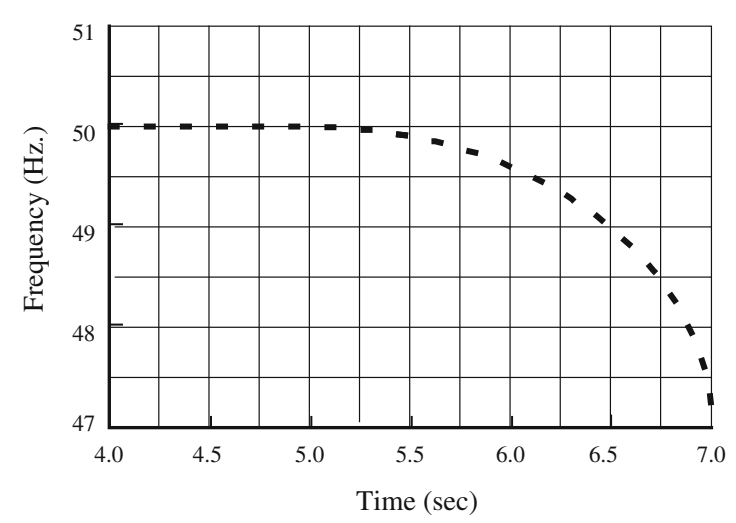

b

Fig. 2 a Islanding easily detected by change in frequency, b Frequency decays slowly and islanding detected after few seconds

Several of these guidelines include the need to provide islanding protection.

The tripping time for the islanding protection should be critically decided such that the two systems are successfully separated first before any out-of synchronism reconnection attempt by automatic reclosure. Currently, the maximum separation time has been specified as $0.5 \mathrm{~s}$; however best target tripping time is $0.125 \mathrm{~s}$ [12]. The fault level of DG Power Island is much less than that of conventional grid and short circuit back-up protection needs to be properly coordinated with this target tripping time. Islanding protection is quite complicated since the Circuit Breaker (CB) that causes the loss of connection could be any breaker or isolator connecting the main source of supply to the DG site. Besides, it is unlikely that the status of the CB is supervised or fitted with synchronism checking or live line/dead bus and live bus/dead line supervision. Thus, for economic viability, there is obvious necessity for low cost, high quality protection packages for the complete protection of the DG system. The use of a single microprocessor based relay with integrated protection functions, including islanding protection, as per the need of the system, is an ideal solution. [13, 14].

Inadvertent islanding presents a number of safety, commercial, power quality, and system integrity problems. In summary, the major issues are [15]:

(i) Line worker safety can be threatened by DG sources feeding a system after primary sources have been opened and tagged out.

(ii) Public safety can be compromised as the utility does not have the capability of de-energizing downed lines.

(iii) The voltage and frequency provided to other utility's control, yet the utility remains responsible to those customers. (iv) Protection systems on the island are likely to be uncoordinated, due to the drastic change in shortcircuit current availability.

(v) The islanded system may be inadequately grounded by the DG interconnection.

(vi) Utility breakers or circuit reclosers are likely to reconnect the island to the greater utility system when out of phase.

\section{Reclosing Coordination}

Many utilities use an 'instantaneous' reclose practice, where breakers and circuit recloses reenergize the protected circuit without any intentional delay. Mechanical operating times typically result in an effective delay of about $150 \mathrm{~ms}$ to $200 \mathrm{~ms}$ from opening to reclosing. Even, where delayed reclosing is used, the shortest delays may be of the order to avoid the possibility of out-of-phase reclosing, the DG must detect the island in a very short period of time, or changes to the reclosing practices must be implemented. Reclosure control changes allowing more latitude for DG coordination includes lengthening the reclosing delay or adding voltage-supervision to reclosing [16]. With voltage supervision, the reclosing is blocked when the downstream system is energized.

\section{Out-of-Phase Reclosing}

The potential for damaging a rotating DG by out-of-phase reclosing is widely understood and appreciated. Large mechanical torques and currents are created, which can damage the generator or the prime mover. Less appreciated is the fact that out-of-phase reclosing can also produce transients which are potentially damaging to utility and other customer equipment. Significant shunt capacitance 
will usually be present in the islanded system in order to provide the reactive power balance required for the island to persist. Out-of-phase reclosing, if it occurs at a voltage peak, will generate a very severe capacitive switching transient. In a lightly damped system, the crest overvoltage can approach three times rated voltage [17]. With more typical damping, the switching transient can exceed 2 p.u. and utility surge arresters and customer equipment are susceptible to damage.

Out-of-phase reclosing can also cause unusually-high inrush currents in transformers and motors. Large transient torques can also occur on motor loads, possibly leading to mechanical damage. Out-of-phase reclose is much more than a DG protection issue. It is a system issue, and due measures are justified to ensure that a DG's islanding protection is coordinated with circuit reclosing practices [18, 19]. The main aspects of power system islanding are reviewed in [20] where islanding schemes are outlined according to graph partitioning and generator grouping. Intentional power system islanding can be used to reduce the amount of load shedding to close to the theoretical minimum. Controlled islanding together with generation and/or load shedding can be used to prevent blackouts in power systems.

\section{Case Study of Existing Islanding Scheme at BTPS}

The $132 \mathrm{kV}$ BTPS bus bar is divided into two sections, Grid Control Room (GCR) switch yard and Electrical Control Room (ECR) switch yard as illustrated in the single line diagram in Fig. 3. It is seen that these switch yards are connected by bus sectionalizer CB called as interconnector 1 and 2. The ECR section has one generator of $62.5 \mathrm{MW}$, $2 \times 25$ MVA, 132/33 kV transformers, 10 MVA, 132/6.6 $\mathrm{kV}$ station transformer, $20 \mathrm{MVA}, 132 / 25 \mathrm{kV}$ railway transformer, 16 MVA, 132/11 kV distribution transformer and five numbers of $33 \mathrm{kV}$ feeders. There is no grid feeder connected to this section. This section gets connected to grid only through interconnector 1 and $2 \mathrm{CB}$. The GCR section consist of $2 \times 210 \mathrm{MW}$ generator units, five grid feeders and four radial feeders as depicted in Fig. 3. Grid feeders were indicated by arrows in both directions; however, radial feeders were indicated by arrows in one direction. Radial feeders of station transformers are minor loads. Therefore, it is not considered in subsequent discussion.

The islanding scheme is applied to ECR section and its salient features are as follows.

(i) $62.5 \mathrm{MW}$ generating unit has provided the islanding scheme. Therefore, this unit is called as IGU after islanding operation. This Unit contains two boilers each having capacity of $30 \mathrm{MW}$ of generation.

(ii) This is a simplest islanding scheme as it can be operated by simply opening the bus sectionalizer CB between stage 1 and 2 which is the only grid connection, that is, interconnector 1 and 2 .

(iii) This section of $132 \mathrm{kV}$ bus associated with Unit I has only transformers are connected. Therefore, there is no need to disturb grid feeders. Following are the constraints to form this islanding scheme.

(a) The raw water pump house which feeds water to this Unit runs on station supply of Stage 2. An alternate source of supply can be made available by utilizing spare of $33 \mathrm{kV}$ feeders at Stage 1.

(b) For most of the time, the radial load is less than the generation of $62.5 \mathrm{MW}$ Unit I. To have better Generation-Demand balance, additional radial load needs to be added or connected. It is assured from the senior level to provide attention. Considering the above constraints, the detail logic of BTPS Stage I islanding has been prepared.

At the instant of islanding when the grid lines are disconnected, the balance between generation and radial loads is very important. This factor decides whether the island will survive. Therefore, while implementing and executing the plan, the load generation balance at post islanding situation has to be achieved. Following two methods achieve this balance [17].

\section{Prediction Method}

This method considers the estimated generation available on bar and estimated radial load for cutting off pre-determined generators and / or radial feeders to achieve closed load-generation balance. This method can be implemented by using simple logics with solid state circuits or relays. For making estimates, statistical figures have to be made available with us. A detail survey of individual loading has to be made with respect to individual radial feeders / generators. This survey has to be done over all times of the day and over all season of the year.

Total generation available on the bar depends on number of units on bar and their actual load / generation. Normally, the loading on each generator is closed to fairly around 80 $\%$ of its rated capacity, irrespective of seasons and peak / off hours. . Therefore, the estimated generation shall be based upon these assumptions. However, the generating unit's outages and their loading constraints can not be predicted. Therefore, even this estimated generation shall not be true for all situations. The main factors for plant stability are (i) Turbine governor response and (ii) Boiler drum level.

\section{On Line Monitoring Method}

This method employs microprocessor based programming logic controller (PLC), fed with actual on line MW data of all generators and radial feeders. By this, PLC will take on- 


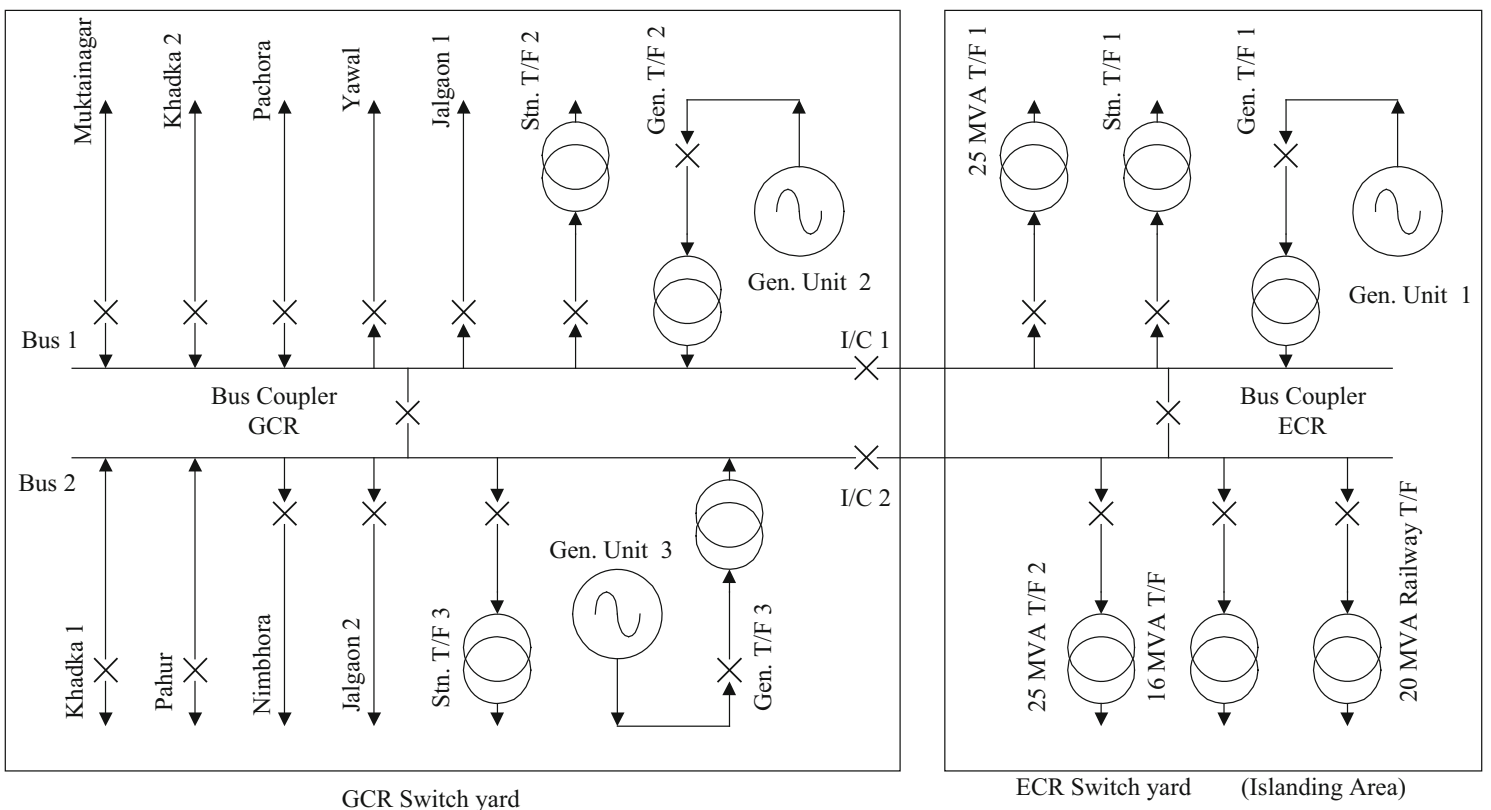

Fig. 3 Single line diagram of BTPS switchyard

line decision for which feeders generators will be tripped to achieve closest load-generation balance. It shall be capable of directly receiving current and voltage signals from CT/ PT of each generator bays and feeder bays in order to derive MW, MVAR, phase angle, etc. It shall thus monitor on-line loading status of each generators as well as radial feeder. Following are the factors on which performance of islanding scheme depends.

(i) Reliability of frequency measurement and frequency relays

(ii) Reliability of CB in obeying trip command

(iii) Reliability of isolator auxiliary contact used for bus/ transfer breaker selection, PT selection, etc.

On execution of islanding command, it is possible; as a rare occurrence; that there is a wide gap between generation-load balances. A wide positive gap belongs to an excess generation situation. This can be on account of following

(i) Individual loading on generators/feeders at that particular instant may vary widely as compared to our estimates.

(ii) Some defects of traditional islanding cause defects in manufactured products, and result in damage to generators in an island. These defects indicate the necessity of self-adaptive islanding researching. Second, an instability mode detection scheme based on out-of-step relays. Variation of voltage and frequency in an island may damage industrial equipment and home appliances. Islanded generation may energize a fault for longer than expected and degrade distribution system reliability due to failed reclosing and defeated fuse-saving protection schemes.

(iii) Inadequate governor response and failure of governor to reduce steam input to turbine.

Such event may be rare, but it can be as manually initiated load throw off test. Therefore, safety of turbine against over-speeding has to be considered. When such sudden load throw is experienced by the machine, the first line of defense will be the action of governor to achieve the balance. The governors are expected to limit the speed rise to $7 \%$ to $8 \%$ even when full load is experienced. However, presently very few governors satisfy this response. In many larger load throw incidences, it is experienced that the mechanical striker operates because the speed rise is not restricted below $4 \%$ to $6 \%$. It reaches to $9 \%$ to $11 \%$. This is due to the deviation in the speed-droop characteristics of governor. Therefore, these may need further tuning depending upon experience as said earlier. A second line of defense, over frequency trip provisions to generators are utilized which may be set at $\pm 5 \%$. The last line of defense is treated to mechanical striker against over speeding.

Islanding visualization techniques are very straightforward. A quick view of two sets of frequency traces will show system separation. The frequency can be graphed, or the phase angle plotted, to show that the systems have become islanded.

The main objective of this islanding scheme is to separate the Unit 1 under circumstance of grid disturbance. Islanding scheme (MICON P 941) commissioned and taken in to circuit on May 18, 2005. However, methods commonly utilized to date focus on the DG islanding detection 
in the distribution systems, and how to divide or split the islanding of large scale power system for preventing a big blackout before the disturbances occur. The tripping contacts of this relaying are connected to tripping coil of circuit breaker of interconnector 1 and 2. Whenever there is a disturbance to GCR side the scheme should have to work satisfactory by separating Unit 1 of ECR side. This scheme works for specified time when the Eq. 1 works satisfactory. The existing setting of Islanding scheme (MICON P 941) is given in Table 1. The islanding scheme performance is discussed with four different case studies and their relevant illustrations also presented as below.

\section{Case 1}

After commissioning and testing, this islanding scheme operated on May 03, 2005 at 15:10 h. The window indication and relay indications are tabulated in Table 2. On May 03, 2005 at 15:10 h., there was sudden disturbance in transmission grid (GCR side) and load of Unit 1 was thrown off from $60 \mathrm{MW}$ to $38 \mathrm{MW}$ and frequency shooted up to $52.24 \mathrm{~Hz}$. Figure 4 indicates the voltage and frequency fluctuation. The ECR side load was about $38 \mathrm{MW}$ and this Unit 1 exporting load to GCR side and it is of $22 \mathrm{MW}$ approximately. The operation is to be based on closed loop system and its objective is to maintain the generationdemand under balance condition for Unit 1 . However, there was neither load tripping scheme commissioned for less generation nor load restoration scheme for more generation. Hence raising or backing of generation need to be carried out manually. As soon as Unit 1 was separated, one of the boilers of Unit 1 was made off. Hence, the generation dropped at $30 \mathrm{MW}$ as illustrated in Fig. 4a. Also, the perfect matching of generation-demand was not possible in a defined period of time. Therefore, at 15:30 h, Unit 1 tripped on under frequency during load control. Islanding period was $20 \mathrm{~min}$, that is, IGU survive for period of $20 \mathrm{~min}$.

\section{Case 2}

This islanding relaying scheme was operated second time on June 16, 2005 at 21:28 $\mathrm{h}$. The window indication and

Table 1 Islanding scheme (MICON P 941)

\begin{tabular}{lc}
\hline Parameter & Setting value \\
\hline Low frequency $\left(f_{L}\right)$ and time $\left(t_{L}\right)$ & $47.6 \mathrm{~Hz}$ and 500 \\
& $\mathrm{~ms}$ \\
Base frequency $\left(f_{B}\right)$ and time $\left(t_{B}\right)$ & $48.0 \mathrm{~Hz}$ and $0 \mathrm{~ms}$ \\
High frequency $\left(f_{H}\right)$ and time $\left(t_{H}\right)$ & $53.0 \mathrm{~Hz}$ and 250 \\
& $\mathrm{~ms}$ \\
Rate of change of frequency setting $\left(\mathrm{d} f_{L} / \mathrm{dt}\right)$ & $600 \mathrm{mHz} / \mathrm{s}$ and 200 \\
and time $(t)$ & $\mathrm{ms}$ \\
\hline
\end{tabular}

relay indications are same as tabulated in Table 2. At this event, there was sudden disturbance in transmission grid (GCR side) due to bursting of current transformer of ' $\mathrm{Y}$ ' phase pertaining to $132 \mathrm{kV}$ Malkapur feeder. At this occurrence, Unit 1 was supplying load of $30 \mathrm{MW}$ as one of the boilers was under maintenance. The load sharing to ECR side was about $12 \mathrm{MW}$ and this Unit 1 exporting load GCR side and it is of $18 \mathrm{MW}$ approximately. Thus, there was a sudden increment in load of $18 \mathrm{MW}$ to ECR side as illustrated in Fig. 5a, and the frequency shooted up to 52.82 $\mathrm{Hz}$. Figures $5 \mathrm{~b}, \mathrm{c}$ indicates the voltage and frequency fluctuation. In this case also, the perfect matching of generation-demand was not possible in a defined period of time. Therefore, at 21:28 h, Unit 1 tripped on over frequency without any load control, this means islanding period was of zero minutes. Thus IGU did not survive for this instant.

\section{Case 3}

Unit 2 and 3, connected to GCR side tripped on over frequency protection due to bursting of lightening arrestor of $132 \mathrm{kV}$ Muktainagar feeder on May 17, 2006 at 18:55 h. At that time, it was heavily raining with lightening and storm. At this time, Unit 1 was sharing $20 \mathrm{MW}$ to $24 \mathrm{MW}$ load and met the load requirement. This Unit 1 was completely islanded successfully and generation-demand was balanced. The window indication and relay indications are same as tabulated in Table 2. But at 21:05 h there was an increment in load demand from ECR side either due to restoration of $33 \mathrm{kV}$ feeders and due to sudden increase in railway traction load. Therefore, the Unit 1 tripped on under frequency condition. Figure 6 illustrates the load position and voltage and frequency fluctuation. In this case, the perfect matching of Generation-Demand was possible and islanding scheme works satisfactory. Islanding period was at the rate $2 \mathrm{~h}$ and $10 \mathrm{~min}$. As the power balance equation was maintained for more than $2 \mathrm{~h}$, IGU survived for this period of time.

Case 4

On February 28, 2007 at 13:11 h, heavy system was experienced in grid due to tripping of $400 \mathrm{kV}$ line in adjoining substation on power swing protection. At this time, grid voltage dropped from $132 \mathrm{kV}$ to $97 \mathrm{kV}$. Unit 3 tripped due to tripping of station transformer on under voltage condition and Unit 2 tripped on under frequency. The window indication and relay indications are same as tabulated in Table 2. At this time Unit 1 was sharing 59.6 MW and both of its boilers were under operating condition. Connected load to ECR side was about 59 MW including railway traction load. In this case $11 \mathrm{kV}$ and $33 \mathrm{kV}$ radial feeders load remains constant, but railway traction load was variable. The railway traction load which was at the 
Table 2 Window indication and relay indications

\begin{tabular}{lll}
\hline S1 No & Window Indications & $\begin{array}{l}\text { Relay } \\
\text { Indications }\end{array}$ \\
\hline 1 & Islanding Relay Operated & MICON P 941 \\
2 & Circuit Breaker of Interconnector 1 Tripped & Master Trip 86-1 \\
3 & Circuit Breaker of Interconnector 2 Tripped & Master Trip 86-2 \\
4 & Unit 1 Separated from GCR (Grid) & \\
\hline
\end{tabular}

rate $20 \mathrm{MW}$ at 13:11 $\mathrm{h}$ dropped to zero at 13:15 $\mathrm{h}$. Hence, due to large difference in generation and demand, Unit 1 tripped on over frequency. Figure 7 illustrates the load position and voltage and frequency fluctuation. In this case also, the perfect matching of generation-demand was possible for certain period of time and islanding scheme works satisfactory. Islanding period was at the rate $4 \mathrm{~min}$, and it was the survival period of IGU.

\section{Solutions for the Survival of IGU at BTPS}

Islanding protection scheme is the need of time as power system is going to become complicated day by day and thereby there will be problem in grid safety. Therefore,

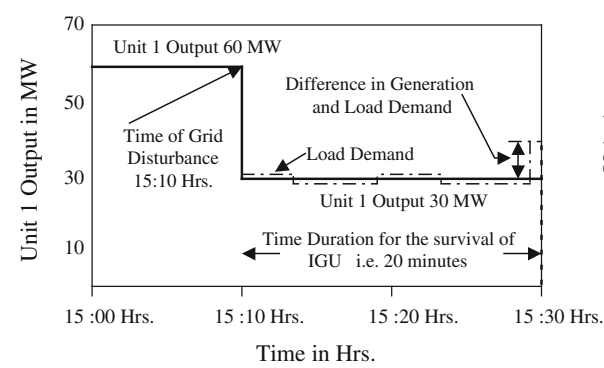

a

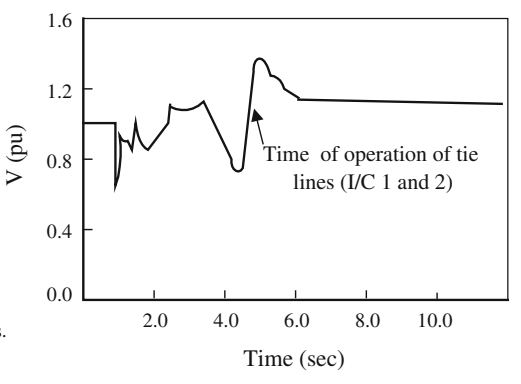

b

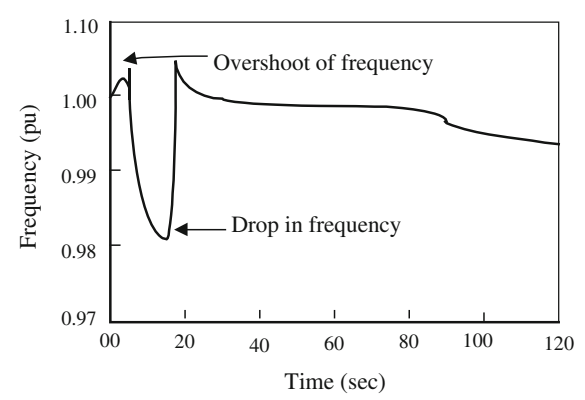

c

Fig. 4 a Generation output of unit 1 after islanding and load pattern, b voltage fluctuation after islanding $\mathbf{c}$ frequency profile after islanding for case 1

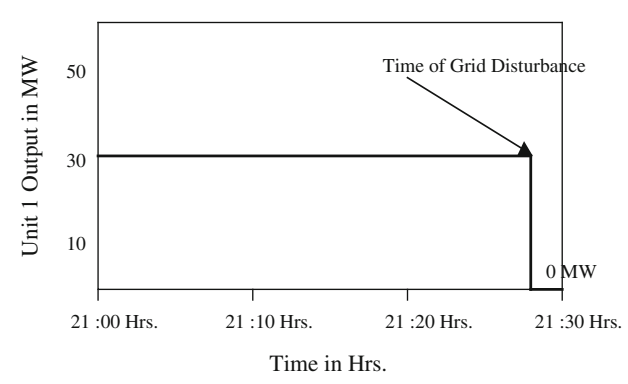

a

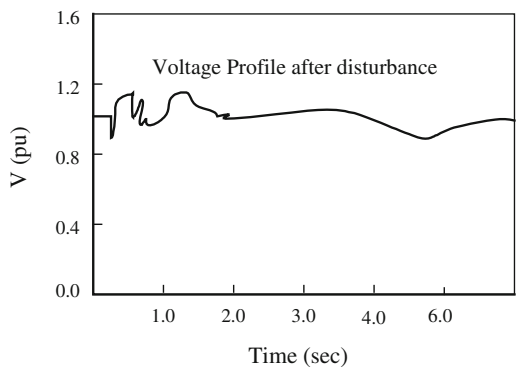

b

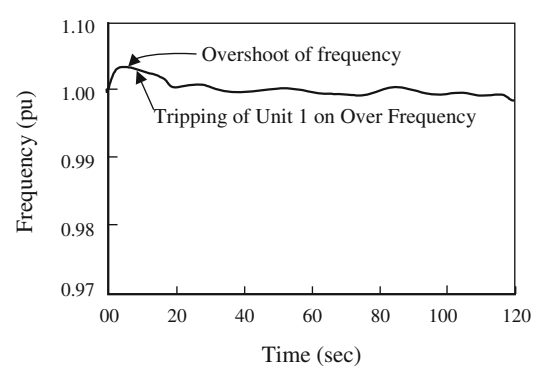

c

Fig. 5 a Generation output of unit 1 after islanding and load pattern, b voltage fluctuation after islanding $\mathbf{c}$ frequency profile after islanding for case 2

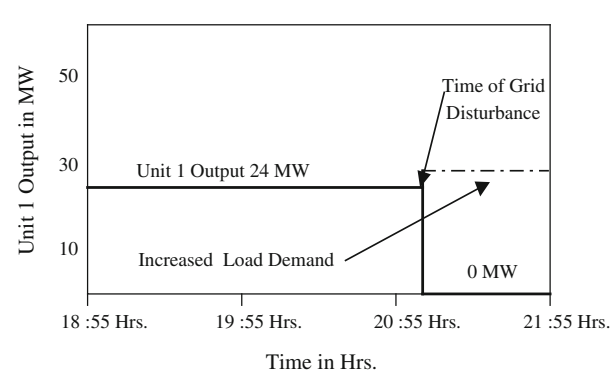

a

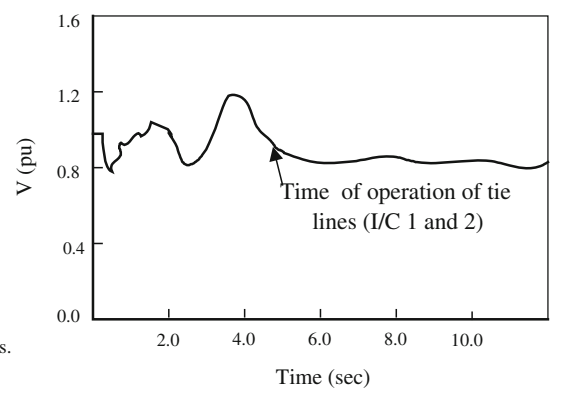

b

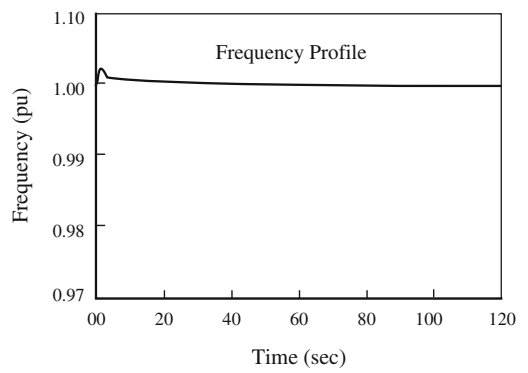

c

Fig. 6 a Generation output of unit 1 after islanding and load pattern, b voltage fluctuation after islanding, $\mathbf{c}$ frequency profile after islanding for case 3 

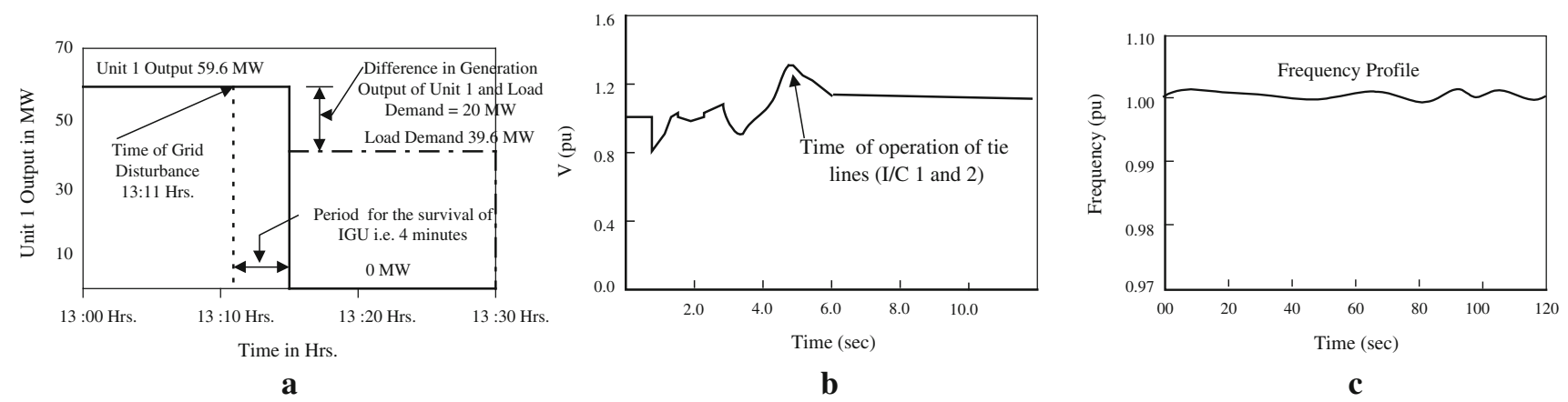

Fig. 7 a Generation output of unit 1 after islanding and load pattern, $\mathbf{b}$ voltage fluctuation after islanding, $\mathbf{c}$ frequency profile after islanding for case 4

minimum one generating unit in major power plant should be provide with islanding protection scheme so that under grid disturbance, this unit will be islanded. Further this IGU not only avoid complete black out, but also help in the grid restoration. For the successful survival of IGU, it should operate under the constraints (1) to (6). Once the grid connected generating unit becomes separate, it means it gets islanded, and then it is the responsibility of the Unit incharge to maintain the IGU under these constraints. From the case studies following are the observations:

1. It is found that, it is difficult for the IGU to get survive under the constraints (1) to (6). The power balance is the essential condition for the IGU is an open loop system. The generation control as well as load control is to be made manually. No automatic generation-load balance system is in service.

2. Raising and backing down of generation of the IGU is a manual task and it is found to be difficult due to improper communication between the operating staff as well as due to poor governing system response. It is found that in Case No. 2, it was difficult to back down the generation in a specified period of time. This IGU is commissioned in 1960, it is a very old generation set and its auxiliary system response was found poor.

3. There is no automatic system commissioned for the raising and backing down of generation to meet the load demand of ECR side. The steam control by governing system and voltage control of exciter of the IGU are responsible for generation output. These two parameters should be controlled according to load requirement.

4. The management of load demand with the generation output is always a crucial task. The load pertaining to ECR side is a variable load. There are railway traction transformers and their load suddenly goes up and down depending upon the travel of train. The railway traction load is uncertain and it is difficult to predict.

5. No effective communication between the generation company (or transmission company) with distribution company after the islanding operation. Therefore, load management according to availability of generation output for the specific IGU is hardly possible. Out of 4 cases it is possible for 1 case only and also for a time period of $2 \mathrm{~h} 10 \mathrm{~min}$.

6. There was no load trimming and restoration scheme commissioned so that no load management can be possible within a frame time period. The load is to be curtailed according to the availability of generation output for IGU. Hence, this should be closed loop system.

From these limitations it is definitely impossible to make efficient survival of the IGU. These lacunae's can be overcome by making use of following solutions. These solutions shall be helpful for the efficient survival of IGU.

1. The existing system is an open loop system and this is the major stumbling block for the IGU survival. The IGU and load demand must be tie up with each other and both of them shall vary accordingly. The closed loop system schematic scheme is illustrated in Fig. 8a. The tie up is provided by the regulator and it controls the generation as well as load demand parameters. The equivalent diagram of this closed loop system with the regulator is shown in Fig. 8b and this is nothing but the match making device. The regulator is shown here by the variable resistance and it can vary either for generator or for load demand.

2. It is possible that the control for the generation parameter is quite difficult task as response from governing mechanism and excitation for the old generating unit is very poor. Considering this fact, the scheme shall be applicable for the load demand control only. Here, it is assumed that the generation output for the IGU is constant and the variable parameter is only the load demand. Therefore, resistive controller shown in Fig. 8b, act towards load variation side only. 


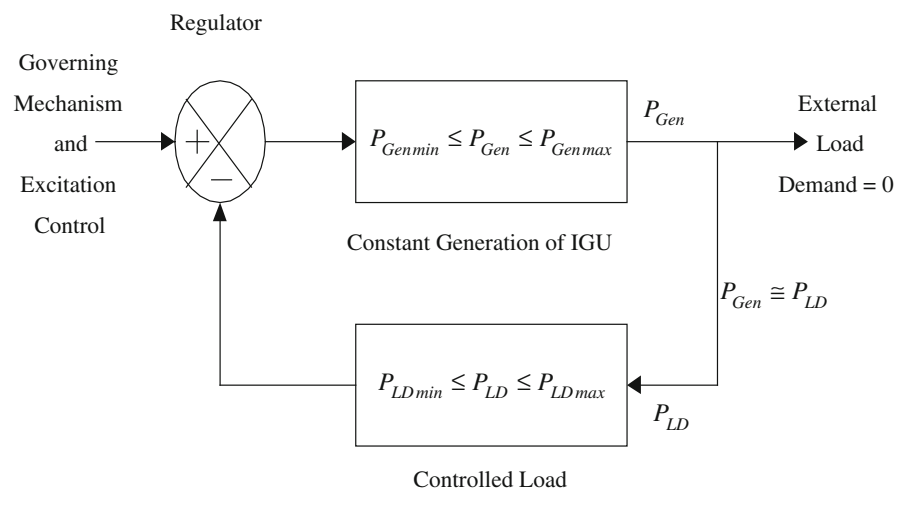

a

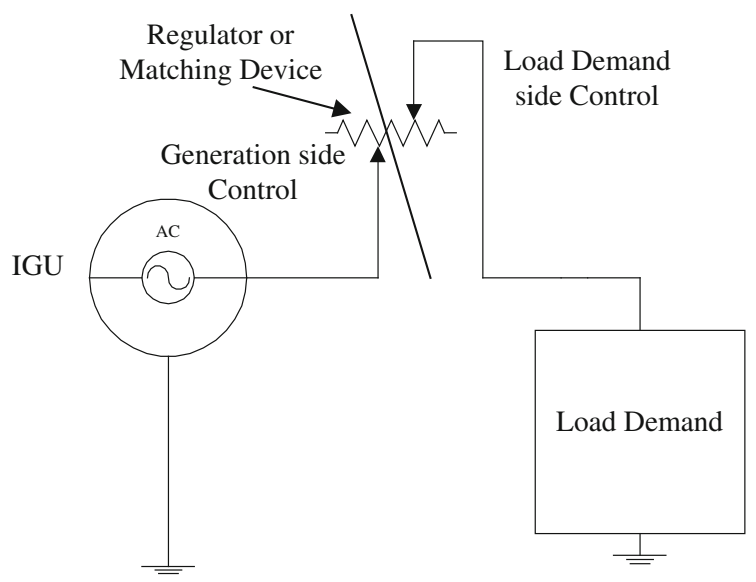

b

Fig. 8 a The closed loop system schematic scheme for the survival of IGU, b equivalent diagram of this closed loop system with the regulator or matching device for the survival of IGU

3. The load trimming and restoration relaying schemes shall be commissioned for the ECR switchyard. These schemes should act in such a fashion that the load demand should get match with the generation output of IGU. This scheme should be the part of regulator or matching device. For perfect matching of load demand with the available generation, the resistive load of sufficient amount should be made ready in ECR switch yards in the form of yard lighting or water pumps, etc. The railway traction load is uncertain and unpredictable; hence it should be removed from ECR switchyard as this might be hampering the performance of regulator.

4. It is mandatory for the regulator or matching device to start just after the opening of CB pertaining to incomer 1 and 2 i. e. just after the islanding of unit 1 of ECR. No delay under any circumstance is desirable otherwise there will be remote chance for the survival of IGU.

5. The relay co-ordination between interconnector 1 and 2 , islanding relay, relaying pertaining to Unit 1 (over frequency relay, under frequency relay, over voltage relay, under voltage relay) and relaying pertaining to load side (under frequency relay, over current relay) should be done properly.

6. The most important factor is the communication between the staff of Generation, Transmission and Distribution Companies and it should be such that it will be helpful for the survival of IGU. It is also suggested that the operating staff should made proper communication with Area Load Dispatch Center and take steps for the restoration of grid on priority.

\section{Conclusion}

The necessity of islanding protection due to causes of power grid disturbance is briefly examined in this paper. The hurdles for the survival of IGU are discussed with case studies of BTPS. The effective survival of IGU is possible with certain constraints and they are positively focused in this article. Intentional power system islanding is the last line of defense for avoiding power system blackout and it also co-operates for grid restoration. Therefore, it is recommended that there should always be single unit in each power plant to which islanding protection should be provided. Lessons learned from some of the major disturbances of the past are presented in the form of four different case studies. The "worst case" problem with power balance is detected reliably. Lacunae's of the existing islanding system are discussed and further the solutions are also provided to overcome these problems. From, these examples it clear that, the islanding scheme is effective and for its successful survival, the closed loop system is desirable.

This study also aims to find the discrepancies in existing islanding scheme so as to make these schemes fast, effective, easy to implement and as maintenance-free as possible. Based on an analysis of the problems to be considered during islanding decision, this paper proposed an effective closed loop system for the survival of islanding condition of the IGU.

\section{References}

1. F. Mura, C. Meyer, R.W. De Doncker, Stability analysis of highpower dc grids. IEEE Trans. Ind. Appl. 46(2), 584-592 (2010) 
2. M. Rylander, W.M. Grady, A. Arapostathis, E.J. Powers, Power electronic transient load model for use in stability studies of electric power grids. IEEE Trans. Power Syst. 25(2), 914-921 (2010)

3. J. Mutale, G. Strbac, S. Curcic, N. Jenkins, Allocation of losses in distribution systems with em bedded generation. IEE Proc. Gener. Transm. Distrib. 147(1), (2000)

4. A. Bertani et al., Electrical energy distribution networks: actual situation and perspectives for distributed generation, proceedings of CIRED, 17th International Conference on Electricity Distribution, Barcelona, Spain, 12-15 May 2003

5. R.H. Lasseter, P. Paigi, Microgrid: a conceptual solution, Proceedings of Power Electronics Specialists Conference(PESC), Aachen, Germany, 6, 4285-4290, 20-25 June 2004

6. L. Kumpulainen, K. Kauhaniemi, Distributed generation and reclosing coordination, Proceedings of Nordic Distribution and Asset Management Conference, NORDAC 2004, Espoo, August 23-24 2004

7. J.A.P. Lopes, N. Hatziargyriou, J. Mutale, P. Djapic, N. Jenkins, Integrating distributed generation into electric power systems: a review of drivers, challenges and opportunities. Electr. Power Syst. Res. 77, 1189-1203 (2007)

8. F.M. Gatta, F. Iliceto, S. Lauria, P. Masato, Modeling and computer simulation of in dispersed generation in distribution networks, measures to prevent disconnection during system disturbances, Proceedings of IEEE Power Tech Conference, Bologna, Italy, June 23-26 2003

9. F.A. Viawan, D. Karlsson, A. Sannino, J. Daalder, Protection scheme for meshed distribution systems with high penetration of distributed generation, Proceedings of Power System Conference 2006: advance metering, protection, control, communication and distributed resources (2006)

10. M. Robitaille, K. Agbossou, M.L. Doumbia, Modeling of an islanding protection method for a hybrid renewable distributed generator, Proceedings of Electrical and Computer Engineering, Canada, 1477-1481, 1-4 May 2005

11. C.G. Bright, COROCOF: comparison of rate of change of frequency protection : a solution to the detection of loss of mains,
Developments in Power System Protection, Conference Publication No. 479 (C) IEE 2001

12. G. Celli, F. Pilo, G. Pisano, V. Allegranza, R. Cicoria, A. Iaria, Meshed against radial MV distribution network in presence of large amount of DG, Proceedings of IEEE PES Power Systems Conference and Exposition, 2, 709-714, 10-13 October 2004

13. S.M. Brahma, A.A. Girgis, Development of adaptive protection scheme for distribution systems with high penetration of distributed generation. IEEE Trans. Power Deliv. 19(1), 56-63 (2004)

14. S.M. Brahma, A.A. Girgis, Effect of distributed generation on protective device coordination in distribution system, Proceedings of Large Engineering Systems Conference on Power Engineering LESCOPE'01, Halifax, Canada, 115-119, 11-13 July 2001

15. S.M. Brahma, A.A. Girgis, Microprocessor-based reclosing to coordinate fuse and recloser in a system with high penetration of distributed generation. Proc. IEEE Power Eng. Soc. Winter Meet. 1, 453-458 (2002)

16. H. Wan, K.K. Li, K.P. Wong, Multi-agent application of substation protection coordination with distributed generators. Eur. Trans. Electr. Power 16(5), 495-506 (2006)

17. M. El-Werfelli, M. Brooks, J.R. Dunn, Controlled islanding scheme for power systems, 43rd International Universities Power Engineering Conference, 2008. UPEC 2008, Padova, 1-6, September 1-4 2008

18. K. Mäki, S. Repo, P. Järventausta, Effect of wind power based distributed generation on protection of distribution network, 8th International Conference on Developments in Power System Protection, Amsterdam, The Netherlands, 327-330, April 2004

19. H.H. Zeineldin, E.F. El-Saadany, M.M.A. Salama, Impact of DG interface control on islanding detection and nondetection zones. IEEE Trans. Power Deliv. 21(3), 1515-1523 (2006)

20. K. Mäki, S. Repo, P. Järventausta, General procedure of protection planning for installation of distributed generation in distribution network. Int. J. Distrib. Energy Resour. 2(1), 1-23 (2006) 